\title{
Transmission electron microscopy study of low-hysteresis shape memory alloys
}

\author{
R. Delville ${ }^{1, a}$, R. D. James ${ }^{2}$, U. Salman ${ }^{3}$, A. Finel ${ }^{3}$ and D. Schryvers ${ }^{1}$ \\ ${ }^{1}$ Electron Microscopy for Materials Science (EMAT), University of Antwerp, Groenenborgerlaan 171, B-2020 \\ Antwerp, Belgium \\ ${ }^{2}$ Department of Aerospace Engineering and Mechanics, University of Minnesota, Minneapolis, Minnesota \\ 55455 , USA \\ ${ }^{3}$ Laboratoire d'Etude des Microstructures, CNRS-ONERA, B.P.72, 92322 Châtillon Cedex, France
}

\begin{abstract}
Recent findings have linked low hysteresis in shape memory alloys with phase compatibility between austenite and martensite. In order to investigate the evolution of microstructure as the phase compatibility increases and the hysteresis is reduced, transmission electron microscopy was used to study the alloy system $\mathrm{Ti}_{50} \mathrm{Ni}_{50-\mathrm{x}} \mathrm{Pd}_{\mathrm{x}}$ where the composition is systemically tuned to approach perfect compatibility. Changes in morphology, twinning density and twinning modes are reported along with special microstructures occurring when the compatibility is achieved. In addition, the interface between austenite and a single variant of martensite was studied by high-resolution and conventional electron microscopy. The atomically sharp, defect free, low energy configuration of the interface suggests that it plays an important role in the lowering of hysteresis. Finally, dynamical modeling of the martensitic transformation using the phase-field micro-elasticity model within the geometrically linear theory succeeded in reproducing the change in microstructure as the compatibility condition is satisfied. Latest results on the extension of these findings in other $\mathrm{Ni}$-Ti based ternary/quaternary systems are also reported.
\end{abstract}

\section{Introduction}

Hysteresis in shape memory alloys (SMA) plays an important role in their thermomechanical behavior with important technological consequences in the design and operation of these materials. Hysteresis is the macroscopic manifestation of the energy dissipated during a phase transformation and which can result in the creation of defects that accumulate over cycling to eventually become the sites of crack initiation [1]. In this way, it is closely related to the fatigue life, an important parameter for applications, especially for systems subjected to cyclic loading. The sources of hysteresis and their relative importance are not yet fully understood because of their actions at different spatial scales [2] and their possible interdependence. At the microscopic scale both the nucleation of the new phase and the interactions of interfaces with defects will contribute to the hysteresis. At larger scales, interactions between domains as well as heat transfer play a role. Recent findings [1] however suggest that interactions at interfaces between the martensitic and austenitic phases during phase transformation might be the dominant phenomenon contributing to hysteresis. This result is supported by the latest developments in the geometric nonlinear theory of martensite (GLNTM) [3, 4] which explains the formation of martensite microstructures, the shape memory effect and the role of crystalline symmetry and phase compatibilities. This theory gives several conditions in order for SMAs to show extremely low hysteresis $[1,3$, 5]. The first condition is no volume change during phase transformation which in mathematical terms translates to $\operatorname{det}(\mathrm{U})=\lambda_{1} \lambda_{2} \lambda_{3}=1$, where $\mathrm{U}$ is the transformation matrix that maps the martensite lattice to the austenite lattice, $\operatorname{det}(\mathrm{U})$ is the determinant and $\lambda_{1} \leq \lambda_{2} \leq \lambda_{3}$ are the ordered eigenvalues of $\mathrm{U}$. The second condition is the phase compatibility between the two phases, i.e. $\lambda_{2}=1$. The austenite is then directly compatible with one variant of martensite. $\lambda_{2}$ is entirely determined by the lattice parameters of austenite and martensite.

When Cui et al. [1] investigated the dependence of hysteresis with these two parameters on composition-spread $\mathrm{TiNiCu}$ and TiNiPd thin films, they discovered a strong correlation between hysteresis and $\lambda_{2}$, but not with $\operatorname{det}(\mathrm{U})$. The same correlation was confirmed by Zhang et al. [6] for bulk alloys of TiNiAu, TiNiPd and TiNiPt. All these alloys show a drop of hysteresis on both sides of $\lambda_{2}=1$ with a singularity at 1 . This finding underlines the importance of phase compatibility for hysteresis which seems to follow a universal behavior as a function of $\lambda_{2}$. The idea behind hysteresis is that the main energy barrier of the phase transformation arises from the bulk energy of this transition layer and the interfacial energy of the twin bands. The growth of a fully developed austenite/martensite interface is costly in energy but it can be greatly reduced by making martensite and austenite compatible. In addition, the transition layer between austenite and two variants of martensite is highly strained $[7,8,9]$ and may relax through the creation of dislocations as evidenced by several TEM studies $[10,11,12]$. The study with electron microscopy of low hysteresis alloys near compatibility

\footnotetext{
a remi.delville@ua.ac.be
}

This is an Open Access article distributed under the terms of the Creative Commons Attribution-Noncommercial License (http://creativecommons.org/licenses/by-nc/3.0/), which permits unrestricted use, distribution, and reproduction in any noncommercial medium, provided the original work is properly cited. 
is therefore an important source of information to understand the impact of phase compatibility on the microstructure and how it relates to low hysteresis $[13,14]$. The $\mathrm{Ti}_{50} \mathrm{Ni}_{50-\mathrm{x}} \mathrm{Pd}_{\mathrm{x}}$ system was chosen because its composition can be tuned to achieve the condition $\lambda_{2}=1$ where it shows a very small hysteresis and it can be easily prepared for TEM investigation.

\section{Experimental methods}

Alloys were prepared from pure elements (99.98 mass\% Ti, 99.99 mass\% Ni, 99.95 mass\% Pd) by arc melting in an argon atmosphere. Slabs of $1 \mathrm{~mm}$ or less in thickness were cut from the ingot by Electrical Discharge Machining and subsequently homogenized at $1100{ }^{\circ} \mathrm{C}$ during $20 \mathrm{ks}$ followed by quenching in room-temperature water. Lattice parameters of both martensite and austenite were measured on a Scintag X-ray diffractometer on polycrystalline slabs previously chemically etched using an electrolyte of $85 \% \mathrm{CH}_{3} \mathrm{COOH}$ and $15 \% \mathrm{HClO}_{4}$. Transformation temperatures and hysteresis were measured by differential scanning calorimetry (DSC) on a TA Instruments Q1000 with $100 \mu \mathrm{m}$ thick slabs, previously etched by the same method. For the TEM study, disks of $3 \mathrm{~mm}$ in diameter were spark-cut or slurry drilled from the slabs, mechanically polished to a $200 \mu \mathrm{m}$ thickness and finally electropolished to perforation in a Tenupol 3 operated at $12 \mathrm{~V}, 0.1 \mathrm{~A},-20^{\circ} \mathrm{C}$ with an electrolyte of 80 $\% \mathrm{CH}_{3} \mathrm{OH}$ and $20 \% \mathrm{H}_{2} \mathrm{SO}_{4}$. CTEM observations were carried out in a Phillips CM20 microscope operated at $200 \mathrm{kV}$ using a side-entry type double-tilt specimen holder with angular ranges of $+/-45^{\circ}$. HREM and CTEM observations were carried out in a FEG Phillips CM30 microscope operated at $300 \mathrm{kV}$ using a side-entry type double-tilt specimen holder.

The $\mathrm{Ti}_{50} \mathrm{Ni}_{50-\mathrm{x}} \mathrm{Pd}_{\mathrm{x}}$ system undergoes a martensitic transformation on cooling from a cubic (B2) to an orthorhombic (B19) lattice for compositions above $\mathrm{x}=7[15,16]$. This transformation gives rise to 6 variants of martensite, noted 1, 2, 3, 4, 5, 6. Lattice parameters of austenite $\left(\mathrm{a}_{0}\right)$ and martensite $(\mathrm{a}, \mathrm{b}, \mathrm{c})$ are listed in table 1 for the different compositions studied, along with $\lambda_{2}$, the middle eigenvalue of any one of the six transformation strain matrices, $\theta_{c}$, defined as the average of the four characteristic transformation temperatures and $H$, the thermal hysteresis.

\begin{tabular}{cccccccc}
\hline Alloys & $a_{0}(\AA)$ & $a(\AA)$ & $b(\AA)$ & $c(\AA)$ & $\lambda_{2}$ & $\theta_{c}(K)$ & $H(K)$ \\
\hline $\mathrm{Ti}_{50} \mathrm{Ni}_{43} \mathrm{Pd}_{7}$ & 3.0318 & 2.8493 & 4.2747 & 4.5474 & 0.9970 & -20 & 26 \\
$\mathrm{Ti}_{50} \mathrm{Ni}_{41} \mathrm{Pd}_{9}$ & 3.0469 & 2.8461 & 4.3036 & 4.5827 & 0.9988 & 40 & 18 \\
$\mathrm{Ti}_{50} \mathrm{Ni}_{40} \mathrm{Pd}_{10}$ & 3.0471 & 2.8436 & 4.3083 & 4.5934 & 0.9998 & 23 & 12 \\
$\mathrm{Ti}_{50} \mathrm{Ni}_{39} \mathrm{Pd}_{11}$ & 3.0499 & 2.8304 & 4.3135 & 4.6041 & 1.0001 & 25 & 13 \\
$\mathrm{Ti}_{50} \mathrm{Ni}_{32} \mathrm{Pd}_{18}$ & 3.0556 & 2.8194 & 4.3429 & 4.6281 & 1.0050 & 113 & 22 \\
$\mathrm{Ti}_{50} \mathrm{Ni}_{30} \mathrm{Pd}_{20}$ & 3.0508 & 2.8202 & 4.3404 & 4.6126 & 1.0060 & 103 & 26 \\
$\mathrm{Ti}_{50} \mathrm{Ni}_{25} \mathrm{Pd}_{25}$ & 3.0625 & 2.8074 & 4.3614 & 4.6667 & 1.0070 & 189 & 32 \\
\hline
\end{tabular}

Table 1. Lattice parameters of the austenite $B 2$ phase $\left(a_{0}\right)$ and the martensite $B 19$ phase $(a, b, c)$ in Angstrom. The middle eigenvalue $\lambda_{2}$ is equal to $b /\left(\sqrt{ } 2 \cdot a_{0}\right)$. It decreases as Pd decreases for the series studied. $\theta_{c}$ is defined as the average of the 4 characteristic transformation temperatures, $\theta_{\mathrm{c}}=(\mathrm{As}+\mathrm{Af}+\mathrm{Ms}+\mathrm{Mf}) / 4$ and the hysteresis as $\mathrm{H}=\mathrm{As}+\mathrm{Af}-\mathrm{Ms}-\mathrm{Mf}$.

\section{Results and discussion \\ 3.1 Evolution of microstructure}

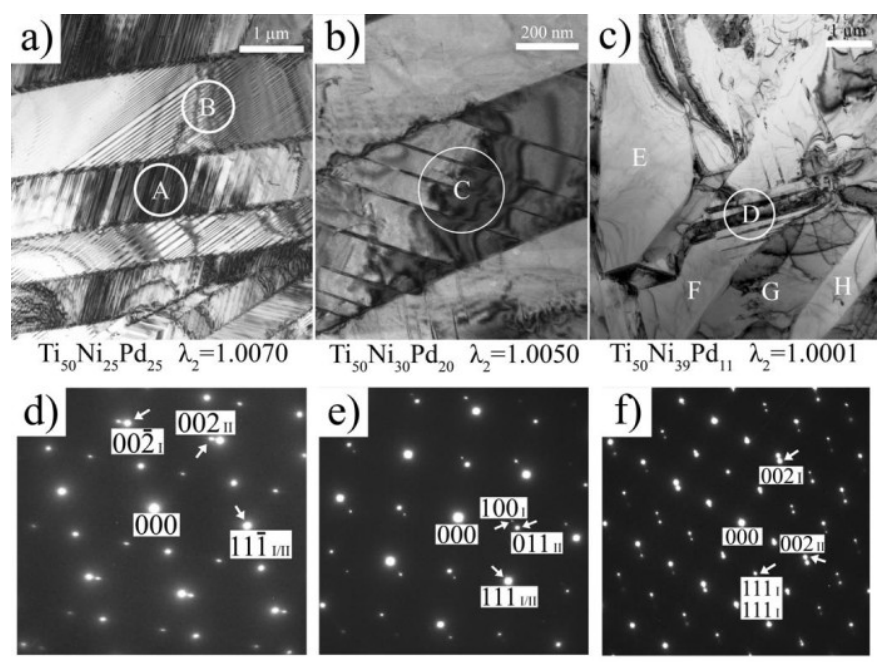

Fig. 1. (a)-(c) shows the evolution of martensite morphology as the content of Pd is decreased towards the compatibility condition $\lambda_{2}=1$. (d) and (e) are SADPs taken from area A and B in (a), respectively. They show $\{111\}$ type I twin pattern in 
[1-10] and [01-1] zone axis, respectively. (c) shows a typical morphology in $\mathrm{Ti}_{50} \mathrm{Ni}_{39} \mathrm{Pd}_{11}$ with twinless martensite plates noted E, F, G, H and a few (011) compound twins in area D as evidenced by the SADP in [100] orientation in Fig. (f).

The alloy with the highest $\mathrm{Pd}$ content, $\mathrm{Ti}_{50} \mathrm{Ni}_{25} \mathrm{Pd}_{25}$, has a $\lambda_{2}=1.0070$, the largest value in the series studied. Its morphology (Fig. 1(a)) is one commonly found in SMAs with long martensite plates constituted of parallel planar layers of twinned martensite variants sometimes referred to as twin laminates. The twin laminates extend diagonally across the width of the martensite plates with rather regular spacing. Their orientations alternate between configuration A and B in successive plates ((Fig. 1(a)). The same relative orientation between successive plates was found throughout the sample. Selected Area Diffraction patterns (SADP) in Fig. 1(d) and 1(e) were taken from the twin laminates in plates A and B (Fig. 1(a)) in two different orientations, the beam edge-on with the twinning plane. Each pattern consists of two sets of reflections which are in mirror symmetry with respect to the (111) plane. The same $\{111\}$ type I twin is found throughout the sample and is considered to be the lattice invariant shear (LIS) which means that martensite is sheared along this mode to accommodate a habit plane with austenite during the phase transformation. Same morphology and LIS twinning of the laminates were reported for higher Pd content $[17,18]$.

As the content of Pd decreases, so does $\lambda_{2}$. $\mathrm{Ti}_{50} \mathrm{Ni}_{30} \mathrm{Pd}_{20}\left(\lambda_{2}=1.0050\right)$ shows some significant changes in its microstructure compared to higher Pd alloys. The lamellar morphology of the martensite plates is partly retained but many plates now exhibit a lower twin ratio or even no twinning. Fig. 1(b) is a bright field (BF) micrograph of a martensite plate in $\mathrm{Ti}_{50} \mathrm{Ni}_{30} \mathrm{Pd}_{20}$ showing a lower twin ratio than in $\mathrm{Ti}_{50} \mathrm{Ni}_{25} \mathrm{Pd}_{25}$. In addition, the surrounding plates do not show any twinning. Overall, the microstructure has a more disorganized morphology, a feature amplified in $\mathrm{Ti}_{50} \mathrm{Ni}_{39} \mathrm{Pd}_{11}$.

$\mathrm{Ti}_{50} \mathrm{Ni}_{39} \mathrm{Pd}_{11}$ has one of the lowest hysteresis from the series shown in Fig. 1 and a $\lambda_{2}=1.0001$, meaning that virtually no lattice invariant shear is required for an undistorted plane (habit plane) to exist during transformation. This compatibility between a single variant of martensite and the austenite matrix allows for twinless transformation that minimizes the overall energy of interfaces, leading to a lower hysteresis. Fig. 1(c) shows an example of microstructure commonly observed in $\mathrm{Ti}_{50} \mathrm{Ni}_{39} \mathrm{Pd}_{11}$. It is composed of a mosaic of micronswide twinless martensite plates as noted by E, F, G, H. The absence of twin laminates inside the plates was also reported for $\mathrm{Ti}_{79} \mathrm{Ta}_{21}$ [19], $\mathrm{Ti}_{49.5} \mathrm{Ni}_{40.5} \mathrm{Cu}_{10}[20,21]$ and $\mathrm{Ti}_{50} \mathrm{Ni}_{30} \mathrm{Cu}_{20}$ [22], which also have a $\lambda_{2}$ close to 1 . The resulting microstructure is determined by the local nucleation conditions and the ensuing growth of twinless martensite plates. One process shaping the microstructure consists in the simultaneous growth of several monovariant plates from one nucleation site in a self-accommodated group of plates (SAG) morphology in order to minimize the transformation strain. SAGs are also observed in $\lambda_{2} \neq 1$ alloys such as binary Ni-Ti $[23,24]$ but the plates are in that case internally twinned.

In $\mathrm{Ti}_{50} \mathrm{Ni}_{39} \mathrm{Pd}_{11}$ triangular SAGs as described by Saburi et al. [21] in TiNiCu were observed. It was first suggested by Saburi and collaborators that 3 variants of martensite self-accommodate around each of the $<111\rangle_{\mathrm{B} 2}$ axis. They proposed a three-dimensional model of the variants self-accommodation as represented in Fig. 2(a). This self-accommodation takes place to minimize the total shape change. An example of a triangular SAG in $\mathrm{Ti}_{50} \mathrm{Ni}_{39} \mathrm{Pd}_{11}$ is presented Fig. 2(d)-(f) showing three BF pictures where the observation axis was tilted from a $\langle 100\rangle_{\mathrm{B} 2}$ (Fig. 2(d), arrow A in Fig. 2(a)) to $\left.<111\right\rangle_{\mathrm{B} 2}$ (Fig. 2(f), arrow B in Fig. 2(a)). The triangular SAG observed in TEM is a two-dimensional section of the three-dimensional variants arrangement. To help understand the relative orientation of the variants taking part in the SAG, a partial stereographic projection between the $[100]_{\mathrm{B} 2}$ and $[111]_{\mathrm{B} 2}$ directions is presented in Fig. 2(b). This figure contains the crystallographic directions of the austenite and variants 2, 4 and 6 which take part in the SAG. Their relative orientation used to plot the projection is defined by the lattice correspondence between the parent phase and the variants listed in table 2 [21]. In addition, $\{111\}_{\mathrm{B} 19}$ planes which form the twin interfaces between variants have been added to the projection. Variants 2, 4, 6 are identified by their respective color and with a subscript in the text. Fig. 2(c) is a schematic representation of cross-sections of the SAG of Fig. 2(a) along the different viewing axis. In the BF picture 2(d) the observation axis is orientated along the $[100]_{\mathrm{B} 2}$ direction of the parent matrix. This is evidenced by the fact that variant 2 (red) is in $[100]_{2}$ zone orientation as shown in the SADP A. This is conform with the relative orientations chosen in the $3 \mathrm{D}$ representation (direction $\mathrm{A}$ ) and in the stereographic projection $\left([100]_{\mathrm{B} 2} / /[100]_{2}\right)$. The stereographic projection also indicates that variant 4 (green) and 6 (blue) have their $[01$ $1]_{4,6}$ axis almost parallel to the $[100]_{\mathrm{B} 2}$ axis and contain the $(111)_{4}$ and $(-111)_{6}$ planes. Experimentally, variants 4 and 6 are observed to meet along a $\{111\}$ type I twin interface (SADP B) in [01-1] orientation with the electron beam slightly tilted from the $[100]_{2}$ direction. This requires a small rotation of the variants to meet along their respective $\{111\}$ planes. When the beam is tilted towards the $[111]_{\mathrm{B} 2}$ axis (from A to B in Fig. 2(a) and arrows in Fig. 2(b)), we tilt around the $\{111\}$ twin plane between variant 4 and 6 . The BF pictures (e) and the SADP C are taken in the intermediary zone $[11-2]_{4} /[-11-2]_{6}$ and show a $\{111\}$ twin SADP. Along the $[111]_{\mathrm{B} 2}$ axis, the three variants $2,4,6$ are oriented along $[10-1]_{2},[10-1]_{4}$ and $[-10-1]_{6}$ directions, respectively. The 3 axes are perfectly parallel and all the variants meet along a twin interface as shown in the SADP D, E, F. To do so, a small rotation of the variants from their initial position described in the stereographic projection is necessary. The angle formed 
by the junction of the three variants depends on the viewing axis. As schematized in Fig. 2(c) the angle between variant 2 and the other variants goes from $90^{\circ}$ in the $[100]_{\mathrm{B} 2}$ orientation to $120^{\circ}$ in the $[111]_{\mathrm{B} 2}$ orientation.
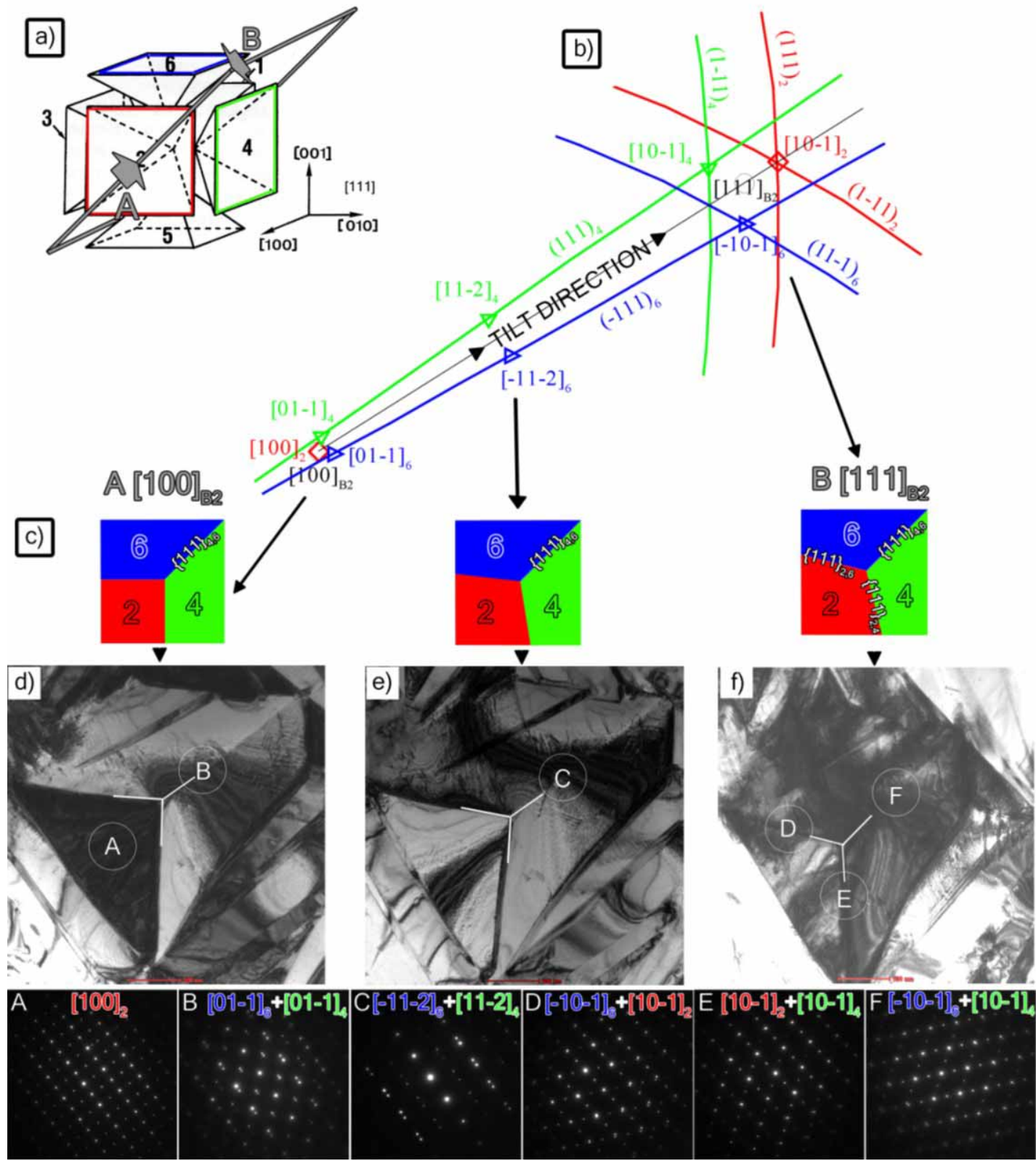

Fig. 2. Triangular SAG. BF pictures (d)-(f) show a tilt series of the SAG. Corresponding SADPs are identified by a circle with a letter. Fig. (a) is a spatial representation of the SAG with the 6 variants. Fig. (b) is a partial stereographic projection with the 3 variants observed in the BF pictures. Fig. (c) is a series of schematic cross-sections perpendicular to the observation axis in the corresponding BF pictures.

\begin{tabular}{llll}
\hline Variants & {$[\mathbf{1 0 0}]_{\mathrm{m}}$} & {$[\mathbf{0 1 0}]_{\mathrm{m}}$} & {$[\mathbf{0 0 1}]_{\mathrm{m}}$} \\
\hline 1 & {$[100]_{\mathrm{p}}$} & {$[011]_{\mathrm{p}}$} & {$[0-11]_{\mathrm{p}}$} \\
2 & {$[100]_{\mathrm{p}}$} & {$[0-11]_{\mathrm{p}}$} & {$[0-1-1]_{\mathrm{p}}$} \\
3 & {$[010]_{\mathrm{p}}$} & {$[101]_{\mathrm{p}}$} & {$[10-1]_{\mathrm{p}}$} \\
4 & {$[010]_{\mathrm{p}}$} & {$[10-1]_{\mathrm{p}}$} & {$[10-1]_{\mathrm{p}}$} \\
5 & {$[001]_{\mathrm{p}}$} & {$[110]_{\mathrm{p}}$} & {$[-110]_{\mathrm{p}}$} \\
6 & {$[00-1]_{\mathrm{p}}$} & {$[1-10]_{\mathrm{p}}$} & {$[-1-10]_{\mathrm{p}}$} \\
\hline
\end{tabular}

Table 2. Lattice correspondence between parent phase (B2) and martensite variants.

of the smallest hysteresis of the series. Fig. 3(a) shows a high resolution micrograph of an interface between austenite and a single variant of martensite in $[011]_{\mathrm{B} 2} /[010]_{\mathrm{B} 19}$ orientation, respectively. This specific orientation was chosen because it is the only one that allows observing the two phases along a main zone axis. The slightly rotated $\left(<4^{\circ}\right)(001)_{\mathrm{B} 19}$ crystallographic planes (upper part) join the $(01-1)_{\mathrm{B} 2}$ planes (lower part) at the interface or

\subsection{Austenite-martensite interface}

To gain further insights into the mechanism of transformation with phase compatibility, it is necessary to study the austenite (B2) / martensite (B19) interface. $\mathrm{Ti}_{50} \mathrm{Ni}_{40} \mathrm{Pd}_{10}$ presents the proper conditions for such a study. First of all, its transformation temperatures lie near room temperature, thus allowing the simultaneous observation of martensite, austenite and their common interfaces. Secondly, with a $\lambda_{2}=0.9998+/-0.0005$, it satisfies exactly the compatibility condition within the error bar and shows one 
habit plane orientated along the $(75-5)_{\mathrm{B} 2}$ plane. When calculating the geometrical lattice spacing mismatch between the B2 and B19 projected along the trace of this plane, one finds only a small mismatch of $0.36 \%$. In other words, the lattice planes join seamlessly at the interface with very little distortions and no misfit defects were detected. This observation indicates a low energy boundary configuration. The image simulation added to Fig. 3(a) was performed using the multislice method implemented in MacTempas. The orientation relationship between the two superimposed lattices used for the simulation was taken from the GNLTM calculations. A color mapping of the $(001)_{\mathrm{B} 19} /(01-1)_{\mathrm{B} 2} \mathrm{~d}$-spacing and the rotation of those planes relatively to a reference orientation was added in Fig. 3(c) and (d), respectively, in order to visualize more clearly the interface. A uniform color signifies a common d-spacing/rotation.
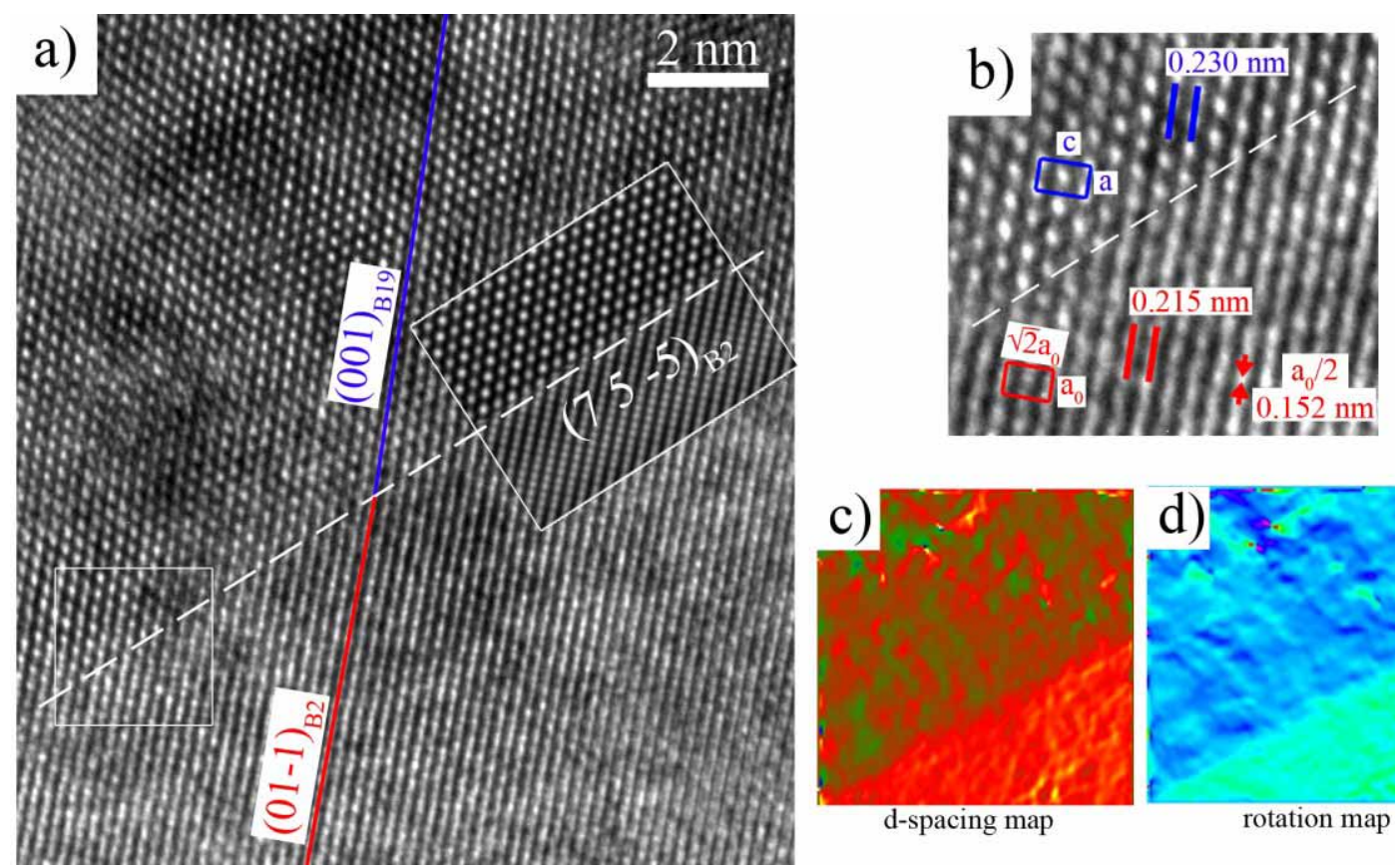

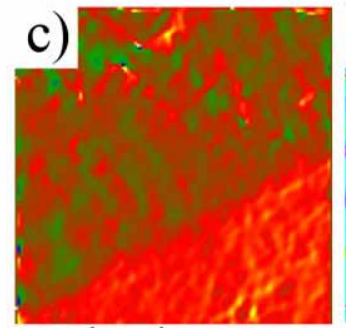

d-spacing map

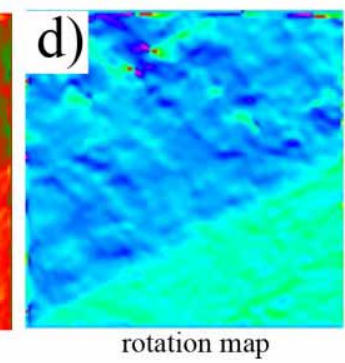

Fig. 3. (a) HREM picture of an austenite/single variant martensite interface. (b) is an enlargement of the inset showing lattice spacing for the two phases. (c) and (d) are a d-spacing map and rotation map of Fig. (a) respectively.

\subsection{Extension to the TiNiAu system}

TiNiAu alloys were prepared following the same experimental procedure as described in section 2. The Ti ${ }_{50} \mathrm{Ni}_{50}$ ${ }_{\mathrm{x}} \mathrm{Au}_{\mathrm{x}}$ system also undergoes a cubic to orthorhombic phase transformation for composition $\mathrm{x}>10$ and exhibits very small hysteresis for certain compositions. Lattice parameters, $\lambda_{2}$, average transformation temperature and hysteresis are listed in table 3.

\begin{tabular}{cccccccc}
\hline Alloys & $a_{0}(\AA)$ & $a(\AA)$ & $b(\AA)$ & $c(\AA)$ & $\lambda_{2}$ & $\theta_{c}(K)$ & $H(K)$ \\
\hline $\mathrm{Ti}_{50} \mathrm{Ni}_{37} \mathrm{Au}_{13}$ & 3.0743 & 2.8901 & 4.3466 & 4.6200 & 0.9997 & 123 & 7 \\
$\mathrm{Ti}_{50} \mathrm{Ni}_{35} \mathrm{Au}_{15}$ & 3.0803 & 2.8820 & 4.3642 & 4.6231 & 1.0018 & 135 & 13 \\
$\mathrm{Ti}_{50} \mathrm{Ni}_{32} \mathrm{Au}_{18}$ & 3.0872 & 2.8886 & 4.4005 & 4.6323 & 1.0079 & 158 & 24 \\
\hline
\end{tabular}

Table 3. Lattice parameters of $\mathrm{Ti}_{50} \mathrm{Ni}_{50-\mathrm{x}} \mathrm{Au}_{\mathrm{x}}$. See table 1 for complete description.

For all the composition studied, $\mathrm{Ti}_{50} \mathrm{Ni}_{50-\mathrm{x}} \mathrm{Au}_{\mathrm{x}}$ exhibits a microstructure similar to the one described for $\mathrm{Ti}_{50} \mathrm{Ni}_{39} \mathrm{Pd}_{11}$. It contains large twinless plates (Fig. 4(a)) as well as a chaotic and/or self-accommodated arrangement of variants (Fig. 4(b)). This is in accordance with their small hysteresis and a $\lambda_{2}$ close to 1 except maybe for $\mathrm{Ti}_{50} \mathrm{Ni}_{32} \mathrm{Au}_{18}$ which has a $\lambda_{2}$ value comparable to $\mathrm{Ti}_{50} \mathrm{Ni}_{25} \mathrm{Pd}_{25}$ but doesn't show the typical laminates morphology observed in the latter. Its hysteresis is however smaller than that of $\mathrm{Ti}_{50} \mathrm{Ni}_{25} \mathrm{Pd}_{25}$. Study of the microstructure for alloys with higher $\mathrm{Au}$ content is under way. Published results on $\mathrm{Ti}_{50} \mathrm{Ni}_{10} \mathrm{Au}_{40}$ and $\mathrm{Ti}_{50} \mathrm{Au}_{50}$ $[25,26]$ show however that alloys have the typical laminate microstructure twinned along the $\{111\}$ type I LIS. 

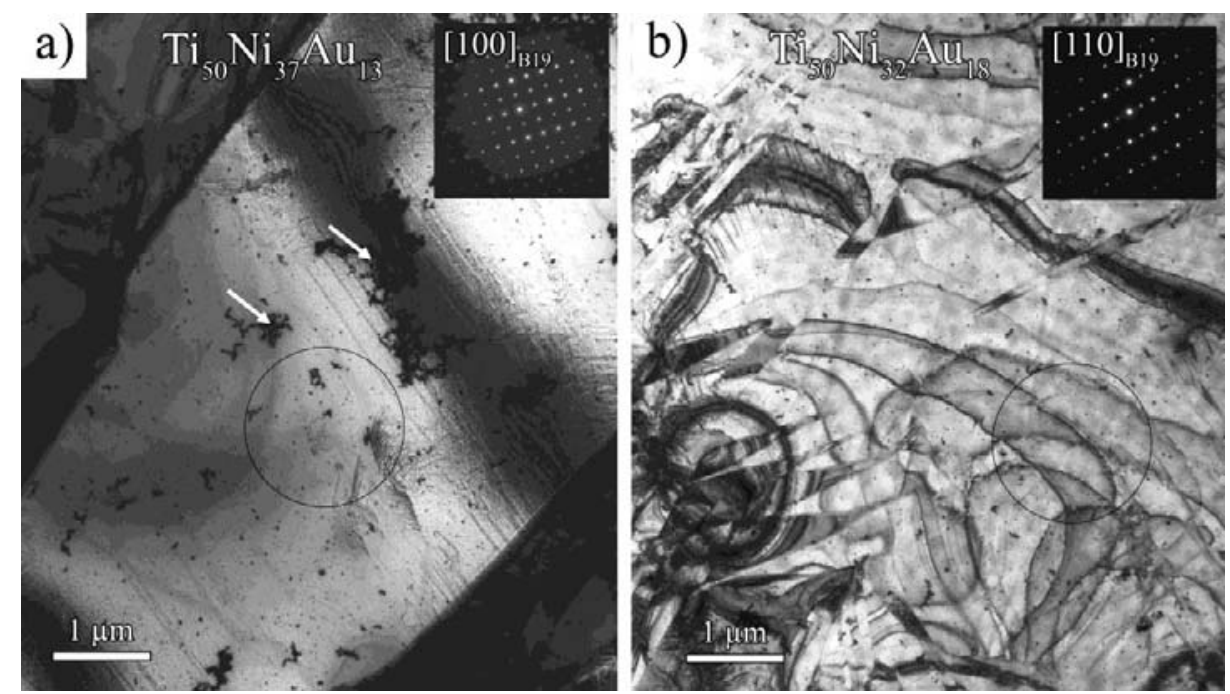

Fig. 4. Examples of large twinless martensite plates in $\mathrm{Ti}_{50} \mathrm{Ni}_{37} \mathrm{Au}_{13}$ (a) and $\mathrm{Ti}_{50} \mathrm{Ni}_{32} \mathrm{Au}_{18}$ (b). The SADP were taken over the circled area inside a large twinless plate. They show B19 reflections in [100] and [110] orientation, respectively. $\mathrm{Ti}_{50} \mathrm{Ni}_{32} \mathrm{Au}_{18}$ shows in addition a chaotic arrangement of other martensite variants. The arrows in Fig. (a) indicate clusters of gold nanoparticles created during electropolishing that have been deposited on the surface of the thin foil.

\subsection{Simulation}

In order to understand the influence of $\lambda_{2}$ on the microstructure evolution, dynamical simulations of a martensitic transformation using a phase-field method with a Time dependent Ginzburg Landau (TDGL) approach were carried out. The microstructure evolution is described by the TDGL equation (1) which controls the evolution of the phase field variable $\eta$, i.e., long-range order parameters describing the distortion introduced by martensite variants.

$$
\frac{\partial \eta(\vec{r}, t)}{\partial t}=-L \frac{\delta F_{\text {total }}}{\delta \eta(\vec{r}, t)}
$$
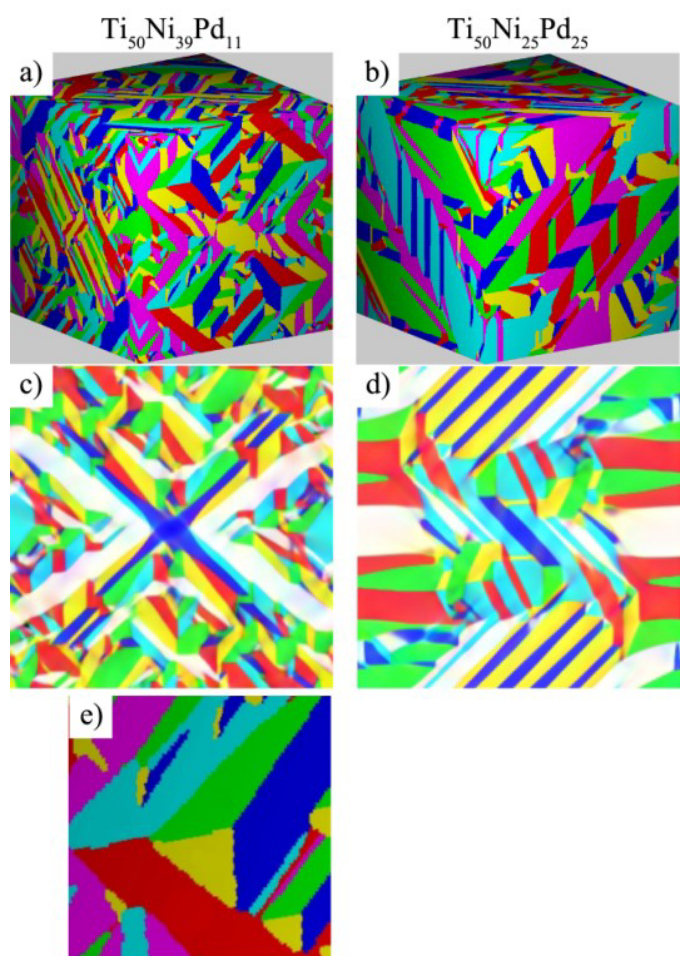

Fig. 5. Results of dynamic simulation of the microstructure for $\mathrm{Ti}_{50} \mathrm{Ni}_{39} \mathrm{Pd}_{11}$ (a, c, e) and $\mathrm{Ti}_{50} \mathrm{Ni}_{25} \mathrm{Pd}_{25}$ (b, d). (a) and (b) are the $3 \mathrm{D}$ rendering of the simulation, (c) and (d) are the middle section along one of the cube axis and (d) is a zoom on a SAG from a section.
$\mathrm{F}$ is the total free energy of the system as a function of structural order parameter $\eta$ and $\mathrm{L}$ is a relaxation coefficient. It contains a strain energy term and chemical energy terms. The strain energy is formulated using geometrically linear elasticity model. Details of the simulation model and conditions will be published elsewhere [27]. We perform simulations corresponding to identical physical problem in terms of thermodynamical potential and interfacial energy but that differ only in terms of lattice parameters. We have chosen to use the lattice parameters of the TiNiPd alloy with $11 \%$ and $25 \% \mathrm{Pd}$ content to monitor the effect of $\lambda_{2}$ on microstructure evolution. Simulations were performed in a box of size $256 \times 256 \times 256$ with repetitive boundaries conditions and with a crystal defect in its center to initiate the martensite nucleation.

We present here only the final microstructure of the dynamical simulation. Nucleation and growth of martensite are described in details in [27]. 3-dimensional rendering (Fig. 5(a)-(b)) and 2dimensional cross-section (Fig. 5(c)-(e)) along one of the cube's axis are presented Fig. 5. We observed that for $\mathrm{Ti}_{50} \mathrm{Ni}_{25} \mathrm{Pd}_{25}(\mathrm{Fig}$. $5(b)$ ), laminates of martensite are a significant feature of the microstructure whereas $\mathrm{Ti}_{50} \mathrm{Ni}_{39} \mathrm{Pd}_{11}$ (Fig. 5(a)) is characterized by a chaotic microstructure presenting numerous SAG such as the one enlarged in Fig. 5(e). These results are, to some extent, in good agreement with the experimentally observed microstructures. The SAG presented in Fig. 5(e) is similar with the SAG presented in Fig. 2. 


\section{Conclusion}

In studying the detailed nature of phase compatibility in the $\mathrm{Ti}_{50} \mathrm{Ni}_{50-\mathrm{x}} \mathrm{Pd}_{\mathrm{x}}$ system, it was found that the microstructure of martensite is dependent on the compatibility parameter $\lambda_{2}$. As predicted by the theory, classical twinning along the lattice invariant shear forming laminated martensite plate was suppressed. Instead, if local conditions allow it, large martensite plates were able to grow untwinned. Otherwise, in areas containing precipitates or defects, the martensite forms a more chaotic or self-accommodated microstructure in order to accommodate the local strains fields. Some SAGs were found to follow the triangular self-accommodation scheme proposed by Saburi et al.

The high resolution study of the interface shows that atomic planes join seamlessly at the interface without misfit defects. The B2 and B19 lattices are very little disturbed and no significant transition layer with a strained lattice could be identified. These observations suggest a low energy boundary configuration. In addition, the same alloy shows an extremely low hysteresis.

The similar microstructures observed for low-hysteresis TiNiAu alloys with a $\lambda_{2}$ close to 1 suggest that the effect of $\lambda_{2}$ on the microstructure, and therefore on the hysteresis, is universal. Due to phase compatibility between austenite and martensite, such alloys have low dissipation of the elastic energy during transformation. Thanks to a good crystallographic fit between the two phases, the stress field at the interface during transformation is minimized and relaxation mechanisms such as the generation of dislocations are reduced.

\section{References}

[1] J. Cui, Y.S. Chu, O.O. Famodu, Y. Furuya, J. Hattrick-Simpers, R.D. James, A.

Ludwig, S. Thienhaus, M. Wuttig, Z. Zhang, I. Takeuchi, Nat. Mater. 5 (2006) p. 286

[2] J. Ortin, L. Delaey, Int. J. Non Linear Mech. 37 (2002) p. 1275

[3] J.M. Ball, R.D. James, Phil. Trans. R. Soc. Lond. A 338 (1992) p. 389

[4] J.M. Ball, R.D. James, Arch. Ration. Mech. Anal. 100 (1987) p. 13

[5] R.D. James, Z. Zhang, Magnetism and Structure in Functional Materials (Springer, New York, 2005, Springer Series in Materials Science)

[6] Z. Zhang, S. Müller, R. D. James, Energy barriers and hysteresis in martensitic phase transformations, submitted to Acta Materialia.

[7] K. Bhattacharya, Microstructure of Martensite (Oxford University Press, 2003), p. 109.

[8] Q.P. Sun, T.T. Xu, X. Zhang, J. Eng. Mat. Tech. 121(1999) p. 38

[9] D. Schryvers and D. Holland-Moritz, Intermetallics. 6 (1998) p. 427

[10] R.F. Hamilton, H. Sehitoglu, Y. Chumlyakov, H.J. Maier, Acta Mater. 52 (2004) p. 3383

[11] R. Sinclair, H.A. Mohamed, Acta Metall. 26 (1978) p. 623

[12] D.M. Norfleet, P.M. Sarosi, S. Manchiraju, M.F.-X. Wagner, M.D. Uchic, P.M. Anderson, M.J. Mills, Acta Mater. 57 (2009) p. 3549

[13] R. Delville, D. Schryvers, Z. Zhang, R.D. James, Scr. Mater., 6 (2009) 293-296.

[14] R. Delville, S. Kasinathan, Z. Zhang, J. Van Humbeeck, R.D. James, D. Schryvers, Phil. Mag., In press.

[15] V.P. Sivokha, A.S. Savvinov Voronin, V.N. Khachin, Phys. Met. Metall. 56 (1983) p. 112

[16] Y.C. Lo, S.K. Wu, Scr. Metall. Mater. 27 (1992) p. 1097

[17] P.G. Lindquist, PhD thesis, University of Illinois at Urbana-Champaign (1988).

[18] M. Nishida, T. Hara, Y. Morizono, A. Ikeya, H. Kijima, A. Chiba, Acta Mater. 45 (1997) p. 4847

[19] K.A. Bywater, J.W. Christian, Philos. Mag. 25-26 (1972) p. 1249

[20] T. Tadaki, C.M. Wayman, Metallography 15 (1982) p. 247

[21] T. Saburi, T. Komatsu, S. Nenno, Y. Watanabe, J. Less-Common Met., 118 (1986) p.217

[22] W.J. Moberly, J.L. Proft, T.W. Duerig, R. Sinclair, Mater. Sci. Forum 56-58 (1990) p. 605

[23] K. Madangopal, Acta mater. 45 (1997) 5347-5365.

[24] S. Miyazaki, K. Otsuka, C.M. Wayman, Acta metal. 37 (1989) p. 1873

[25] T. Inamura, R. Tachi, K. Wakashima, H. Hosoda, Mater. Res. Soc. Symp. Proc. 980 (2007)

[26] S.K. Wu, C.M. Wayman, Metallography 20 (1987) p. 359

[27] O. Salman, R. Delville, S. Schryvers, A. Finel, in preparation 